\title{
Use of Microwaves for Damage Detection of Fiber Reinforced Polymer-Wrapped Concrete Structures
}

\author{
Maria Q. Feng, A.M.ASCE ${ }^{1}$; Franco De Flaviis²; and Yoo Jin Kim³
}

\begin{abstract}
Jacketing technology using fiber reinforced polymer (FRP) composites is being applied for seismic retrofit and rehabilitation of reinforced concrete (RC) columns designed and constructed under older specifications. In this study, the authors develop an electromagnetic (EM) imaging technology for detecting such damage as voids and debonding between the jacket and the column, which may significantly weaken the structural performance of the column otherwise attainable by jacketing. This technology is based on the reflection analysis of a continuous EM wave sent toward and reflected from layered FRP-adhesive-concrete medium: Voids and debonding areas will generate air gaps which produce additional reflections of the EM wave. In this study, dielectric properties of various materials involved in the FRP-jacketed RC column were first measured using a plane-wave reflectometer. The measured properties were then used for a computer simulation of the proposed EM imaging technology. The simulation demonstrated the difficulty in detecting damage by using plane waves, as the reflection contribution from the voids and debonding is very small compared to that from the jacketed column. In order to alleviate this difficulty, dielectric lenses were designed and fabricated, focusing the EM wave on the bonding interface. Finally, three concrete columns were constructed and wrapped with glass-FRP jackets with various voids and debonding conditions artificially introduced in the bonding interface. Using the proposed EM imaging technology involving the especially designed and properly installed lenses, these voids and debonding areas were successfully detected. This technology can be used to assess the jacket bonding quality during the initial jacket installation stage and to detect debonding between the column and the jacket caused by earthquake and other destructive loads.
\end{abstract}

DOI: 10.1061/(ASCE)0733-9399(2002)128:2(172)

CE Database keywords: Microwaves; Damage; Concrete structures; Fiber reinforced materials; Polymer; Imaging techniques.

\section{Introduction}

The enhanced structural performance of reinforced concrete $(\mathrm{RC})$ columns retrofitted by fiber reinforced polymer (FRP) composite jackets has been well demonstrated and an increasingly large number of bridge and building columns have been retrofitted with such jackets in the United States and elsewhere. However, seismic damage such as debonding between the jacket and the column that can considerably weaken the column remains a significant concern, as such damage cannot be visually identified. Also, a jacket is made of several layers of FRP composites often manually applied to the column, layer by layer, glued with adhesive epoxy. Hence, the bonding quality between the layers of the composite jacket and between the jacket and column causes additional concern, as it heavily depends on the workmanship.

\footnotetext{
${ }^{1}$ Associate Professor, Dept. of Civil and Environmental Engineering, California Institute of Telecommunications and Information Technology, Univ. of California, Irvine, CA 92697-2175. E-mail: mfeng@uci.edu

${ }^{2}$ Assistant Professor, Dept. of Electrical and Computer Engineering, Univ. of California, Irvine, CA 92697-2175.

${ }^{3}$ Research Associate, Dept. of Civil and Environmental Engineering, California Institute of Telecommunications and Information Technology, Univ. of California, Irvine, CA 92697-2175.

Note. Associate Editor: Farhad Ansari. Discussion open until July 1, 2002. Separate discussions must be submitted for individual papers. To extend the closing date by one month, a written request must be filed with the ASCE Managing Editor. The manuscript for this paper was submitted for review and possible publication on October 18, 2000; approved on June 8, 2001. This paper is part of the Journal of Engineering Mechanics, Vol. 128, No. 2, February 1, 2002. CASCE, ISSN 0733-9399/2002/2$172-183 / \$ 8.00+\$ .50$ per page.
}

Poor bonding conditions, particularly the existence of large areas of voids and/or debonding, can significantly degrade the structural integrity and safety that could otherwise be attainable by jacketing. This has been demonstrated by the results of the experiment performed by Haroun and Feng (1997). In that study, three identical half-scale circular bridge columns with lap splices were built. Two of the columns were wrapped with identical glass-FRP jackets: one was well wrapped with the adhesive epoxy carefully applied to the entire jacketing area, while the other was poorly wrapped with many voids in the bonding interface. Force-displacement envelops resulting from the cyclic loading tests of the three columns (unwrapped, poorly wrapped, and well wrapped) are shown in Fig. 1. The well-wrapped column performed excellently by increasing the column ductility factor from less than 2 (unwrapped column) to 6 . The poorly wrapped column with many voids barely reached the ductility factor of 3 . However, the voids and debonding areas could not be visually observed. Tapping with a hammer and listening to the sound may help to detect such damage, but cannot quantify the extent of damage.

Various nondestructive evaluation (NDE) techniques have been studied to detect cracks of concrete structures and debonding or delamination between concrete and rebars, including $\mathrm{x}$ - and gamma-ray radiography, computerized radioactive tomography based on X- and gamma-rays, radar, and acoustic techniques. Some of them appear very promising for application in civil engineering structures such as bridges, highways, asphalt pavements, sewer systems and wastewater pipes, canals and aqueduct, and buildings (Buyukozturk 1998). An ultrasonic imaging method for detecting cracks in steel bridges has been developed by a 


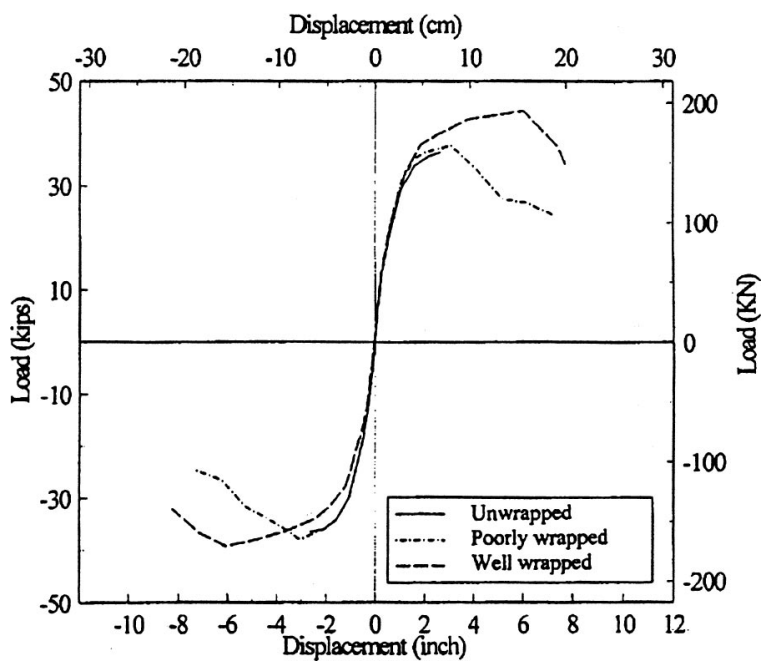

Fig. 1. Void and performance degradation (Haroun and Feng 1997).

project sponsored by the Federal Highway Administration (Chase and Washer 1997). Other research projects have demonstrated the potential to detect voids in concrete using ultrasonic tomography (Olson et al. 1993), although the results are influenced by sizes and shapes of aggregates. Recently, the Lamb and longitudinal ultrasonic wave scanning techniques were investigated for detecting delamination between a glass-FRP plate and a concrete surface, and the Lamb wave scanning technique appeared to be the superior technique (Kundu et al. 1999). Ultrasound, however, cannot penetrate deeply inside highly attenuative materials such as fibers in FRP and epoxy resins used for the matrix materials (Kundu et al. 1999). It is also highly sensitive to the maximum aggregate size (Buyukozturk 1998). Ground penetrating radar (GPR) is widely used to detect anomalies in a material. Small and reliable devices producing very short pulses ( $0.2 \mathrm{~ns})$ able to obtain spatial resolutions in the range of centimeters have been fabricated and used as single sensors and also as arrays of sensors for imaging purposes (Mast et al. 1998). A good impedance match antenna (GIMA) GPR system for concrete structure assessment has the capacity to detect concrete cracks as small as $1 \mathrm{~mm}$ thick, while being able to reflect from and detect features at depths of up to $360 \mathrm{~mm}$ (Huston et al. 2000). GPR-based NDE technology has not been studied for FRP-jacketed RC columns. The only available technology at this moment for evaluating the bonding condition of FRP-jacketed columns is infrared thermography (Johnson et al. 1999). The authors, in fact, have worked with the Aerospace Corporation to test the effectiveness of this technology in detecting voids and debonding areas in FRP-jacketed RC columns. Infrared thermography, by nature, is not very accurate because of the continuous distribution of heat and the amplitudeonly measurement of the heat signal. It is impossible to detect the radial location and depth of voids. Also, it is difficult to use this technology for deep detection, especially when involving thick composite jackets. In addition, the heat applied to the column for building a thermographic profile may change the property of FRP materials, especially before the materials are fully cured.

In this study, extending an earlier analytical work (Feng et al. 2000a) and preliminary experimental work (Feng et al. 2000b,c), an electromagnetic (EM) imaging technology is developed and verified for its capability to assess the bonding condition of FRPjacketed RC columns. This paper will present (1) an overview of the proposed technology; (2) the measurement of dielectric prop-

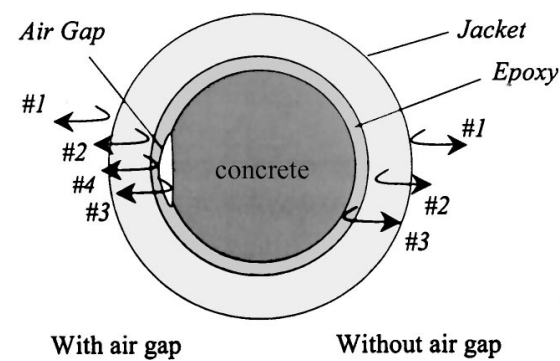

Fig. 2. Reflection mechanism in jacketed reinforced concrete column

erties of the materials involved in a jacketed concrete column; (3) a computer simulation based on the measured properties to demonstrate the difficulty in detecting the voids/debonding using plane waves, and also to study the optimal experimental setup; (4) design of a special lens for focusing the plane waves on the bonding interface; and (5) an experiment on FRP-jacketed concrete columns, which successfully assessed the bonding condition by innovative instrumentation that utilizes the dielectric focusing lens and other devices.

\section{Overview of Proposed Technology}

The proposed EM imaging technique is based on the analysis of a continuous EM wave sent toward and reflected from a layered medium. It is well known that when a plane EM wave is launched from an illuminating device (typically an antenna or a lens) towards a layered medium and encounters a dielectric interface, a fraction of the wave energy is reflected, while the rest is transmitted into the medium. In the case of a RC column wrapped with a layer of FRP jacket subjected to the incoming wave, as shown in Fig. 2, the first reflection (No. 1) occurs at the surface of the jacket, while the second (No. 2) at the interface between the jacket and the adhesive epoxy, and the third (No. 3) at the interface between the adhesive epoxy and the concrete, assuming the jacket is perfectly bonded to the column without a void or debonding. In addition, reflections from the interface between the concrete and steel reinforcing rebars and from the sources internal to the illuminating device will also take place. If there is an air gap resulting from a void or debonding between the composite jacket and the column, an additional reflection (No. 4) will occur at this particular location, as illustrated in Fig. 2. Therefore, imperfect bonding conditions can be, in principle, detected by analyzing these reflections in the time and/or in the frequency domains.

\section{Measurement of Dielectric Properties Using Plane Wave Reflectometer}

The accurate measurement of the dielectric properties of the different materials in a FRP-jacketed RC column was the first part of this study. Such properties, including the dielectric constant and conductivity, are needed for the simulation analysis of the proposed EM imaging technique.

For the measurement, flat material sample sheets, each with an equal dimension of $25.5 \mathrm{~cm}$ by $21.5 \mathrm{~cm}$, were made from glass fiber reinforced polymer, carbon fiber reinforced polymer, and concrete, respectively. The experimental setup is shown in Fig. 3. A material sample sheet was inserted in a reflectometer, which 


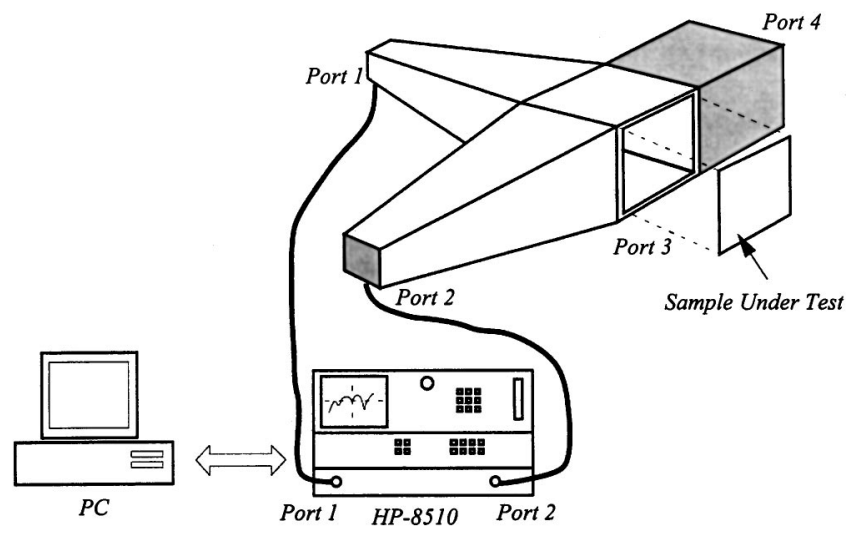

Fig. 3. Experimental setup for dielectric property measurement

was connected to an automatic network analyzer (ANA) HP-8510 and further to a personal computer (PC).

The dielectric properties of each material were measured from the response of the material sample to plane wave excitation in free space. There are usually two fundamental difficulties associated with the measurement of the free-space reflection and transmission with respect to the material sample: First, it is difficult to generate a uniform plane wave; and second, unwanted parasitic reflections and multiple reflections are produced in the measurement path. Fortunately, with its very special design, the reflectometer used in this study virtually eliminates both of these problems (Flaviis et al. 1996; 1997a). A photograph of the reflectometer is shown in Fig. 4.

The design of the reflectometer is based on the use of a hollow metal dielectric waveguide (HMDW) as the EM wave transmission line structure or medium. The HMDW consists of a large (compared to the wavelength) rectangular waveguide with thin nonresonant dielectric and absorber layers on two opposite walls, or on all four walls. The useful operating mode of this transmission structure is the mode $\mathrm{LM}_{11}$. It is a linearly polarized longitudinal magnetic wave with a simple field structure (no nulls) over both transverse directions within the interior. In addition, special tapered waveguide transitions are used to transform the transmission mode from the standard waveguide $\mathrm{TE}_{10}$ mode (for the X-band in the evaluation unit) to the $\mathrm{LM}_{11}$ mode of the reflectometer. The aperture of the reflectometer is of the order of 7 wavelengths by 7 wavelengths square (this is $200 \mathrm{~mm}$ by $200 \mathrm{~mm}$

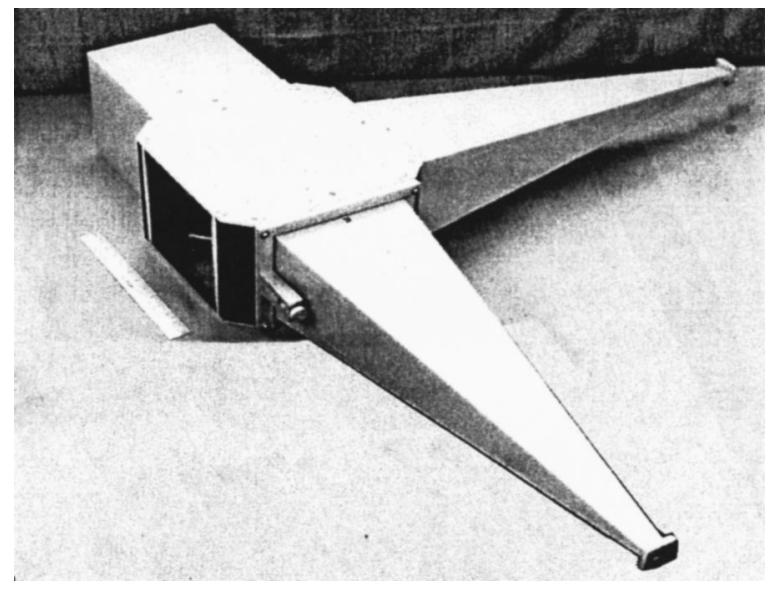

Fig. 4. Hollow metal dielectric waveguide reflectometer
Table 1. Measurement of Dielectric Properties

\begin{tabular}{lcc}
\hline $\begin{array}{l}\text { Sample } \\
\text { number }\end{array}$ & Relative dielectric constant $\left(\varepsilon_{r}\right)$ & Conductivity $(\mathrm{S} / \mathrm{m})$ \\
\hline 1 & $10.87\left(10.8^{\mathrm{a}}\right)$ & 0.33 \\
2 & $2.45\left(2.33^{\mathrm{a}}\right)$ & 0.22 \\
3 & $1.07\left(1.02^{\mathrm{a}}\right)$ & 0.0 \\
4 (E-glass) & 3.84 & 0.18 \\
5 (concrete) & 5.30 & 0.05 \\
\hline
\end{tabular}

${ }^{a}$ Nominal value.

for the X-band evaluation unit). The $\mathrm{LM}_{11}$ mode of the reflectometer has several unique properties. First, this mode has very low losses. Second, the longitudinal field components are small, that is, the field is nearly transverse electromagnetic, and hence, it is almost a plane wave. Third, the longitudinal currents at the waveguide walls are vanishingly small. This results in very small diffraction at any transition from this waveguide to free space. These features figure prominently in the design and operation of the HMDW reflectometer. The small diffraction of the $\mathrm{LM}_{11}$ mode from the edges at the waveguide-to-space transition keeps the parasitic reflections from the aperture perimeter at the test plane very low. Having very low parasitic reflections from the aperture allows the instrument to be effectively used for the characterization of samples with very small reflection coefficients such as the FRP composites, which have dielectric constants in the range of $2-4$.

As shown in Figs. 3 and 4, the reflectometer has four ports. A microwave signal from port 1 of the ANA is fed into the small end of the tapered transition connected to port 1 of the HMDW cross-directional coupler, and is converted from the TE mode to LM mode. The signal passes through the HMDW crosswaveguide coupler at port 1 . Part of the signal goes to the load at port 4, while most of the signal passes through to the sample under test at port 3. The reflection from the sample returns through port 3 and in turn splits into a minor component that passes through to the source arm at port 1 and a major component that is coupled to the receiver/detector arm at port 2 of the HMDW coupler. The coupled signal passes through the waveguide transition of arm 2 and onto port 2 of the ANA. The magnitude of the received signal at port 2 of the ANA is proportional to the magnitude of the reflection coefficient of the material sample under test.

A computer program on a PC was developed in this study for controlling the reflectometer calibration/measurement and related ANA functions, estimating the reflection coefficients, relative dielectric constants and conductivity of the material samples. The measurements for the different materials are listed in Table 1. Material sample Nos. 1, 2, and 3 shown in Table 1 were used for calibration purposes. The comparison between the measured and nominal values of these samples demonstrates that the special reflectometer is capable of measuring dielectric properties with high accuracy.

\section{Simulation Analysis Using Finite-Difference Time-Domain Method}

\section{Modeling}

Using the dielectric properties of the materials measured from the above experiment, a computer simulation was performed to examine whether the plane EM wave is appropriate to use for de- 


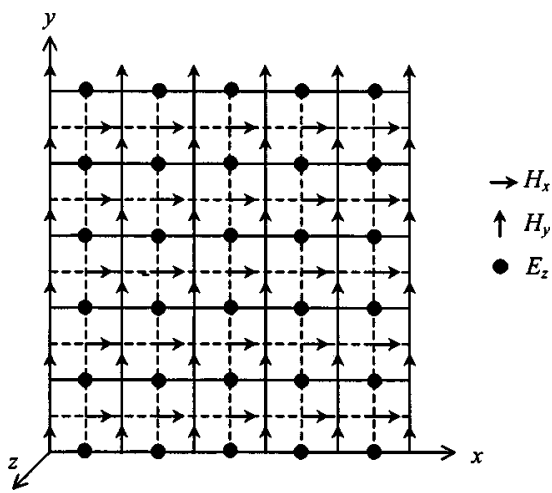

Fig. 5. Finite-difference time-domain grid

tecting imperfect bonding conditions of a jacketed RC column and also to study the optimal experimental setup.

For the computer simulation, the finite-difference time-domain (FDTD) method was used. The FDTD method, introduced by Yee (1966), is a numerical technique for solving Maxwell's equation expressed in a differential form. It is based on a central difference approximation for the estimation of partial derivatives of the governing differential equations. In order to obtain the FDTD solution for a given problem, space and time are discretized. Space is modeled as a grid constructed of Yee cells in which the components of the electromagnetic field vectors are located in a manner suitable for the implementation of a central difference approximation to Maxwell's equations. A portion of the FDTD grid used in this study for the two-dimensional (2D) case is presented in Fig. 5 . The field configuration for this $2 \mathrm{D}$ model is that of the transverse magnetic (TM) mode and the reduced set of Maxwell's equations involves only the $E_{z}, H_{x}$, and $H_{y}$ components of the electromagnetic fields.

The FDTD solution is obtained directly in the time domain through an iterative process in which the values of the field components at Yee cells are updated using the FDTD equations. An iteration of this process corresponds to a time step. Because of the use of a central difference approximation, the time derivatives of the magnetic and electric fields are evaluated half a time step apart, respectively. The time step $(\Delta t)$, with which the solution is advanced, cannot be assigned arbitrarily, but is related to the spatial step $(\Delta s)$ by the stability condition presented by Courant,
Friedrich, Levy (CFL), and von Neumann (Taflove 1995). For the $2 \mathrm{D}$ case, the stability condition requires that

$$
\Delta t \leqslant \frac{\Delta s}{c \sqrt{2}}
$$

where $c$ is the speed of light. An important factor in FDTD modeling that must be accounted for is numerical dispersion. That is, the phase velocity of numerical wave modes in the FDTD grid can differ from the vacuum speed of light, $c$, varying with the wavelength, the direction of propagation in the grid, and the grid discretization (Taflove 1995). In order to avoid the numerical dispersion, grid size is bounded by

$$
\Delta s \leqslant \frac{\lambda}{10}
$$

where $\lambda$ is the wavelength. Boundary conditions are introduced at the outer boundaries of the computational domain. At the outer boundary, the second-order Mur absorbing boundary condition is utilized in order to simulate unbounded space beyond the computational domain (Taflove 1995).

The incident wave for the model is a Gaussian pulse plane wave, $g(t)=e^{-\left(t-t_{0}\right)^{2} / T^{2}}$, where $g(t)$ is the electric field of an incident wave $(\mathrm{V} / \mathrm{m}), t$ is time $(\mathrm{s}), t_{0}$ is the time delay $(\mathrm{s})$, and $T$ is the pulse width at an $80 \%$ level of the peak amplitude. In this study, the incident Gaussian pulse was chosen to have maximum frequency $f_{\max }$ of $25 \mathrm{GHz}$ and pulse width $T$ of $0.02 \mathrm{~ns}$, which was calculated from $T=1 / 2 f_{\max }$. The Gaussian pulse in the time domain with time delay $t_{0}$ of $0.06 \mathrm{~ns}$ and a pulse width of $0.02 \mathrm{~ns}$ is shown in Fig. 6.

The computational domain used in this study was discretized to 90 by 300 square grids, each having a size of $1.0 \mathrm{~mm}$ by 1.0 $\mathrm{mm}$, as shown in Fig. 7. The physical size of the computational domain was $9 \mathrm{~cm} \times 30 \mathrm{~cm}$. The response from the concrete column was measured at point $A$. The FRP-jacketed concrete column is modeled as layered media with the FRP jacket glued by adhesive epoxy to a concrete column. An air gap is introduced between the adhesive epoxy and concrete to simulate a debond.

\section{Simulation Results}

At first, an incident plane wave was sent toward the jacketed column at an angle perpendicular to the surface of the jacketed

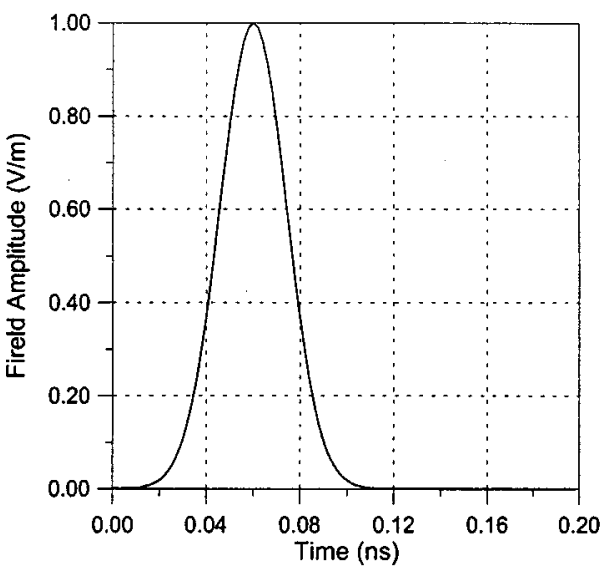

(a) Incident wave in time domain

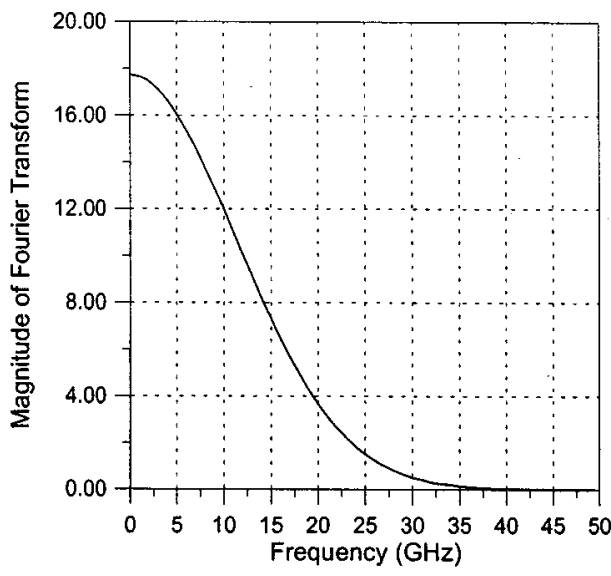

(b) Incident wave in frequency domain

Fig. 6. Incident wave of Gaussian pulse 


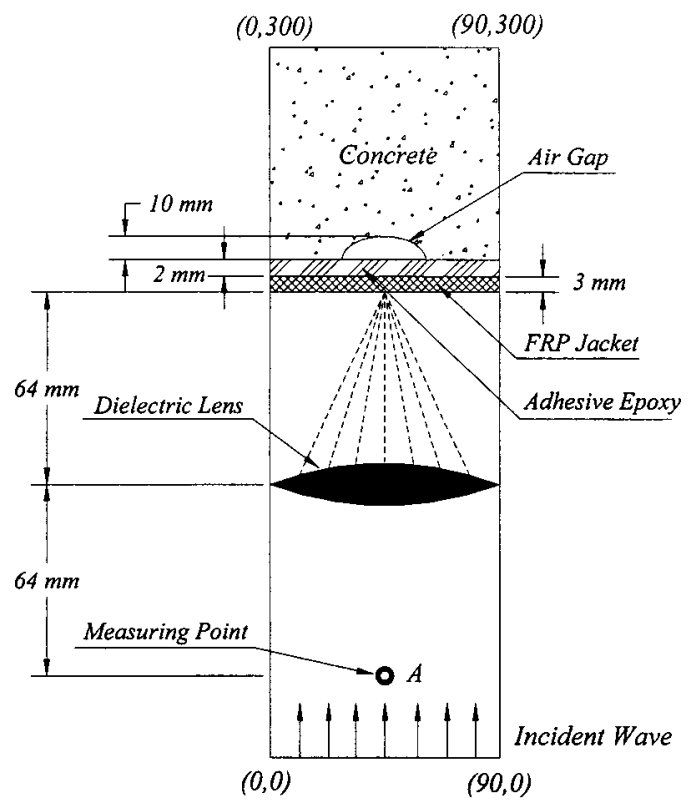

Fig. 7. Finite-difference time domain modeling of fiber reinforced polymer-jacketed reinforced concrete column with air gap $\left(90^{\circ}\right.$ setup)

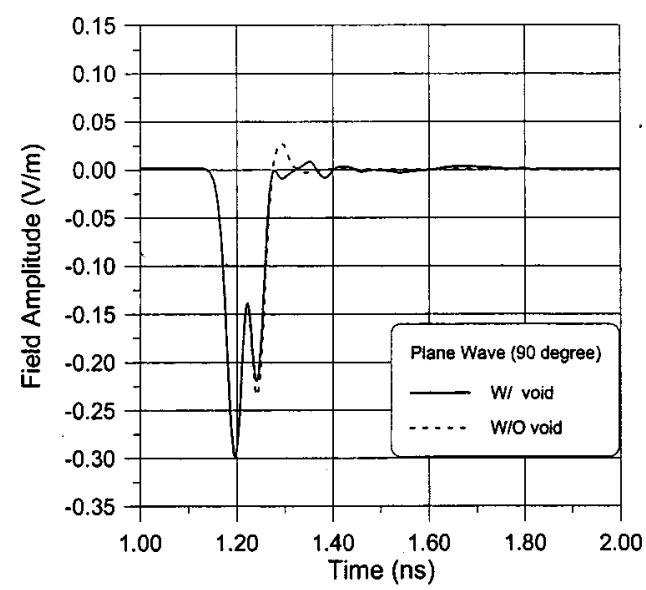

(a) $90^{\circ}$ Setup (Time Domain)

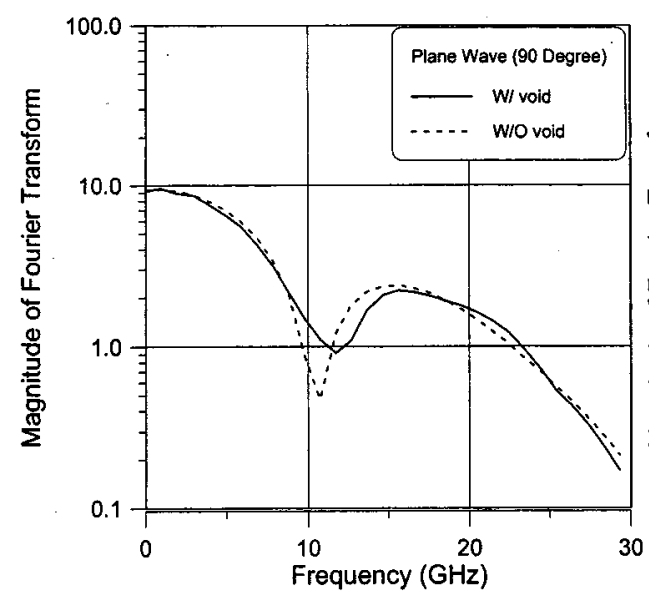

(c) $90^{\circ}$ Setup (Frequency Domain) column, and the reflection from the jacketed column was measured. It was found that the difference of the reflections between perfect bonding and debonding conditions could not be detected, as shown in Figs. 8(a) and 8(c). The reason is that the reflection that occurred at the surface of the jacketed column is much stronger than the additional reflection due to the air gap. In order to overcome this difficulty, a $45^{\circ}$ setup was introduced to remove the surface reflection from the measured response. In this setup, the $45^{\circ}$ angle between the wave direction and the surface of the jacketed column minimizes the portion of the reflection from the jacketed column that returns to the measuring point. Therefore, additional reflections can be measured if there are imperfect bonding conditions. The comparison of the reflections from the jacketed concrete column with and without the void is shown in Figs. 8(b and d). However, it is still not easy to distinguish the difference caused by the void, because the reflection contribution of the void is very small compared to that of the jacketed column itself.

In this study, it is proposed to use a dielectric lens in order to significantly improve the effectiveness of the technique. A dielectric lens can focus the EM waves on an interested region, i.e., the bonding interface of a jacketed column. The concept and design of the dielectric lens will be presented in the next section. Fig. 9 shows the results of the numerical simulation using focused waves generated by a dielectric lens, with the $90^{\circ}$ and $45^{\circ}$ setups.

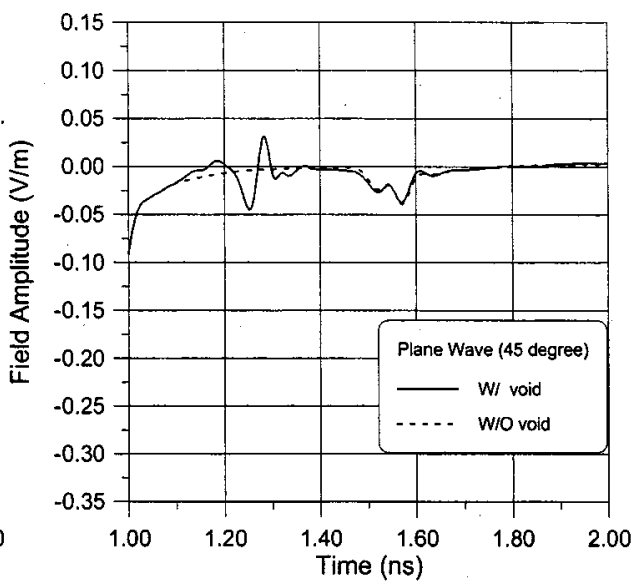

(b) $45^{\circ}$ Setup (Time Domain)

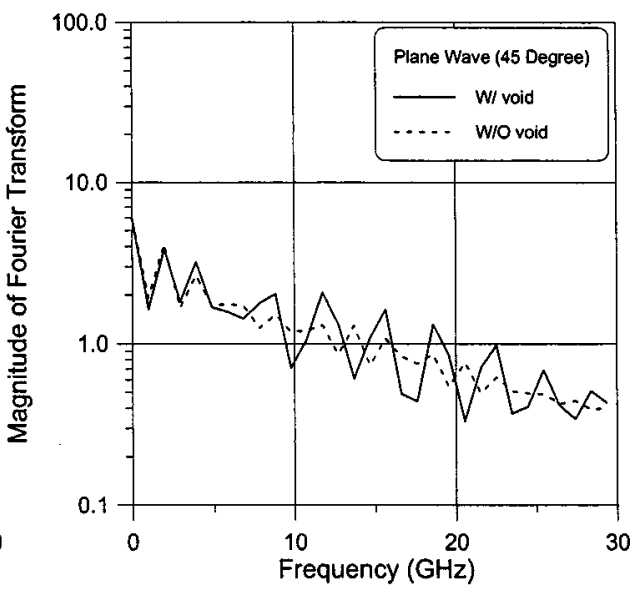

(d) $45^{\circ}$ Setup (Frequency Domain)

Fig. 8. Reflected wave in time and frequency domains (using plane wave) 


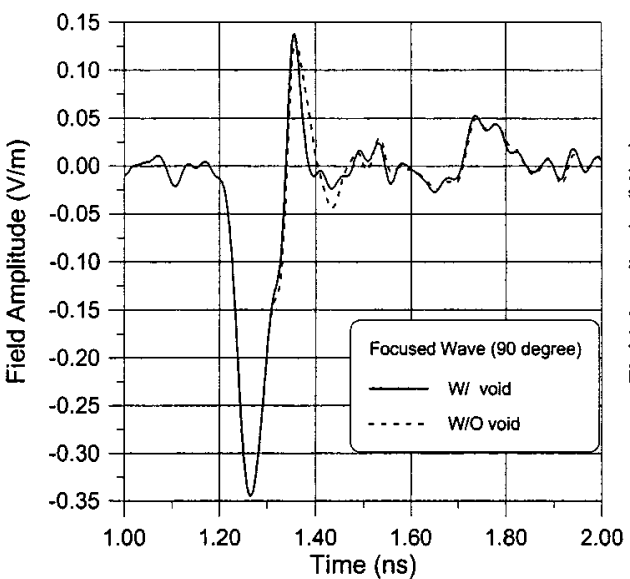

(a) $90^{\circ}$ Setup (Time Domain)

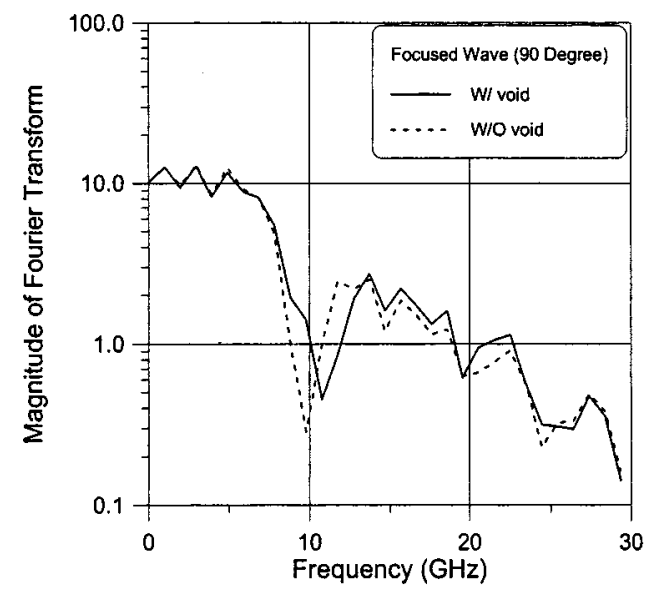

(c) $90^{\circ}$ Setup (Frequency Domain)

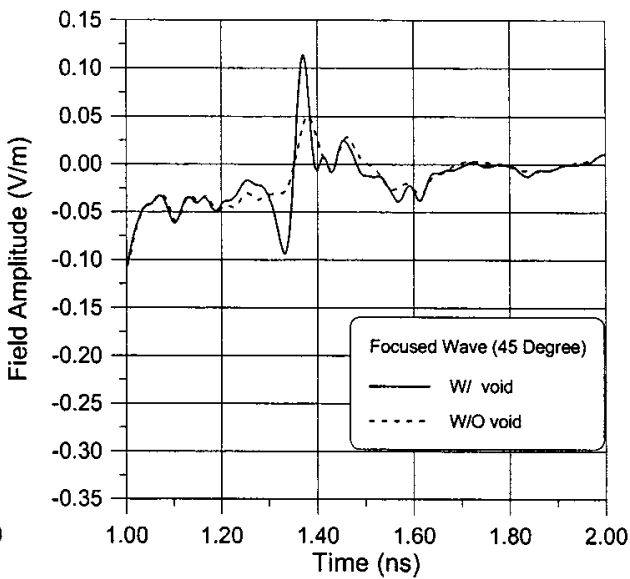

(b) $45^{\circ}$ Setup (Time Domain)

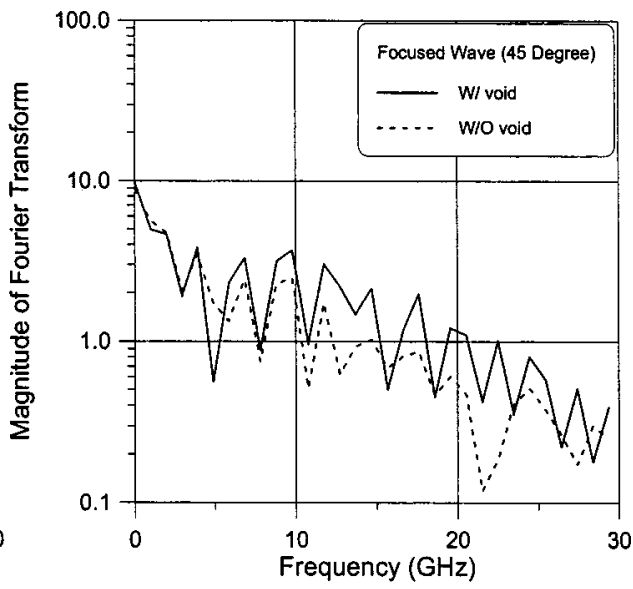

(d) $45^{\circ}$ Setup (Frequency Domain)

Fig. 9. Reflected wave in time and frequency domains (using focused wave)

The reflections from the jacketed columns with and without the void are clearly different. The difference is much larger than that when using the plane wave shown in Figs. 8(b and d).

From this preliminary simulation analysis, it can be concluded that the focused EM wave generated by a dielectric lens is more effective than the plane EM wave in distinguishing the imperfect bonding condition from the perfect one. It is also demonstrated that the $45^{\circ}$ setup is more efficient than the $90^{\circ}$ setup when using a single dielectric lens to send the wave and receive the reflection.

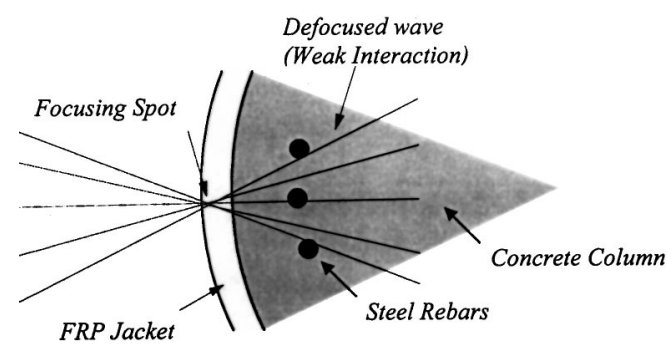

Fig. 10. Use of dielectric lens to focus waves on bonding interface

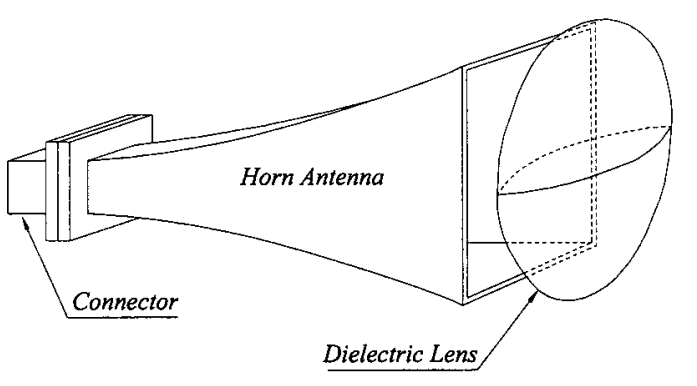

(a) Circular lens

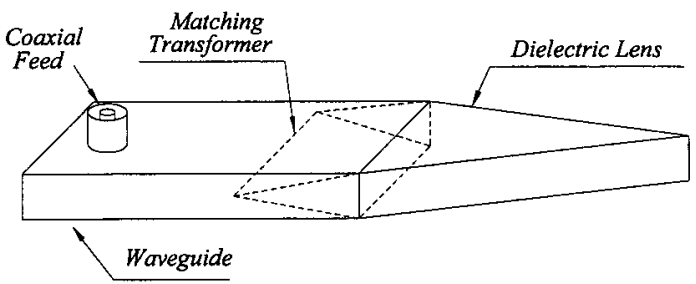

(b) Triangular lens

Fig. 11. Dielectric lenses designed 


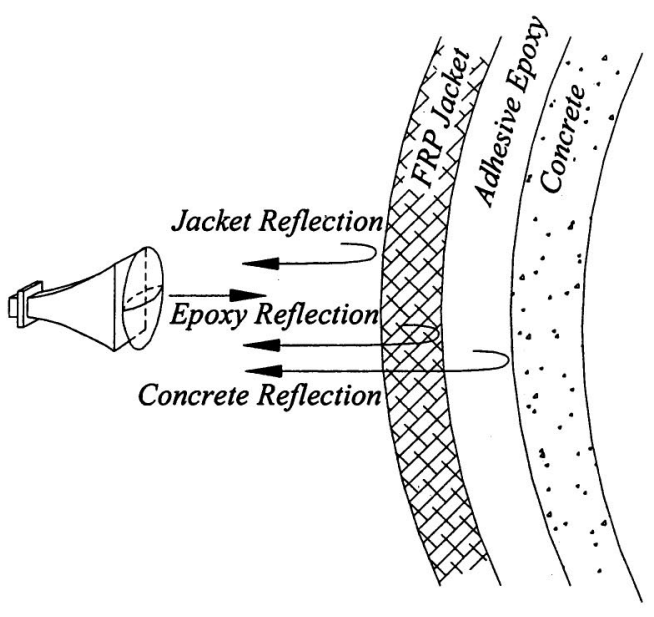

Reflection Measurement (S11)

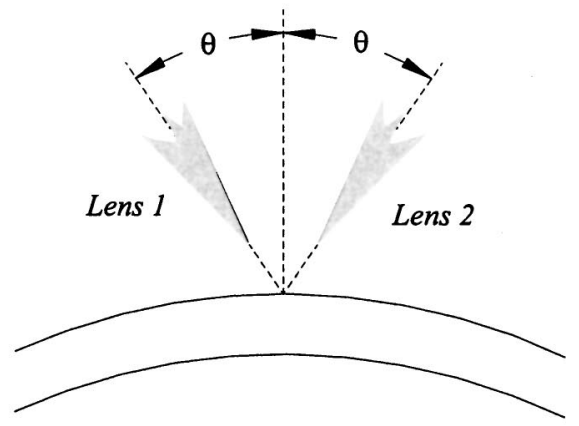

Transmission Measurement (S21)

Fig. 12. Setup for reflection and transmission measurement

\section{Lens Design}

In order to overcome the difficulty associated with the plane EM wave, a dielectric lens was used to focus the EM wave on the bonding interface of the jacketed column, while diffusing the field in other regions of no interest, as illustrated in Fig. 10. Waves reflected from the other regions where the beam is defocused will be much weaker than those from the focused region. The difference between the perfect and poor bonding conditions in the focused region can be detected more effectively.

In this study, two types of lens were designed, as shown in Fig. 11: one in triangular and the other in circular shape. The triangular lens is not optimized for the reflection measurement $\left(S_{11}\right)$, so the transmission measurement $\left(S_{21}\right)$ using two lenses, as shown in Fig. 12(b), is required. In other words, one lens is used to transmit waves and the other to receive the reflected waves. The angle $2 \theta$ between the two lenses shown in Fig. 12(b) should be adjusted to achieve the best wave reception quality. The circular lens can be attached in front of the horn antenna. It is optimized for the reflection measurement $\left(S_{11}\right)$ in which one lens not only transmits but also receives waves.

\section{Experimental Verification on FRP-Jacketed Concrete Columns}

\section{Test Specimen and Damage}

The effectiveness of the proposed EM imaging technology using focused EM waves was investigated through a series of experiments on a concrete panel and FRP-jacketed concrete columns.

The $25.5 \mathrm{~cm}$ by $21.5 \mathrm{~cm}$ by $4.0 \mathrm{~cm}$ concrete panel has a hole on the surface and a FRP sheet is attached to the panel by clamps. The diameter of the hole is about $2 \mathrm{~cm}$ and the depth of it is about $1 \mathrm{~cm}$. The surface of the concrete panel is not perfectly flat and smooth, so small gaps exist between the concrete surface and the FRP sheet.

Three concrete columns of $40.64 \mathrm{~cm}$ (16 in.) in diameter and $81.28 \mathrm{~cm}$ (32 in.) in height were built without rebars. Each of the columns was wrapped with a three-layer glass FRP jacket. The thickness of each layer is $1.143 \mathrm{~mm}$ (0.045 in.). Various voids and debonding conditions were artificially introduced between the jackets and the columns and between the layers of the jackets. Some voids were caused by the holes of $1 \mathrm{~cm}$ depth on the con-

Table 2. Damage Description

\begin{tabular}{lll}
\hline $\begin{array}{l}\text { Case } \\
\text { number }\end{array}$ & \multicolumn{1}{c}{ Description } \\
\hline 1 & $\begin{array}{l}\text { Void caused by a hole on the concrete surface }(2.0 \mathrm{~cm} \mathrm{diam}) \\
2\end{array}$ & $\begin{array}{l}\text { Void caused by a hole on the concrete surface }(2.0 \mathrm{~cm} \mathrm{diam}) \\
05^{\circ}(\text { column } 1)\end{array}$ \\
3 & $\begin{array}{l}\text { Debonding caused by a rectangular Styrofoam }(1.0 \mathrm{~cm} \times 1.0 \\
\mathrm{cm} \times 1.0 \mathrm{~cm}) \text { inserted between FRP and concrete column }\end{array}$ \\
4 & $\begin{array}{l}\text { Debonding caused by a rectangular Styrofoam }(1.0 \mathrm{~cm} \times 1.0 \\
\mathrm{cm} \times 0.5 \mathrm{~cm}) \text { inserted between FRP and concrete column }\end{array}$ \\
5 & $\begin{array}{l}\text { Debonding caused by a rectangular Styrofoam }(2.0 \mathrm{~cm} \times 2.0 \\
\mathrm{cm} \times 0.5 \mathrm{~cm}) \text { inserted between FRP and concrete column }\end{array}$ \\
6 & $\begin{array}{l}\text { Debonding from top to bottom caused by a Styrofoam strip }(1.0 \\
\mathrm{cm} \times 1.0 \mathrm{~cm}) \text { between FRP and concrete column }\end{array}$ \\
\hline
\end{tabular}




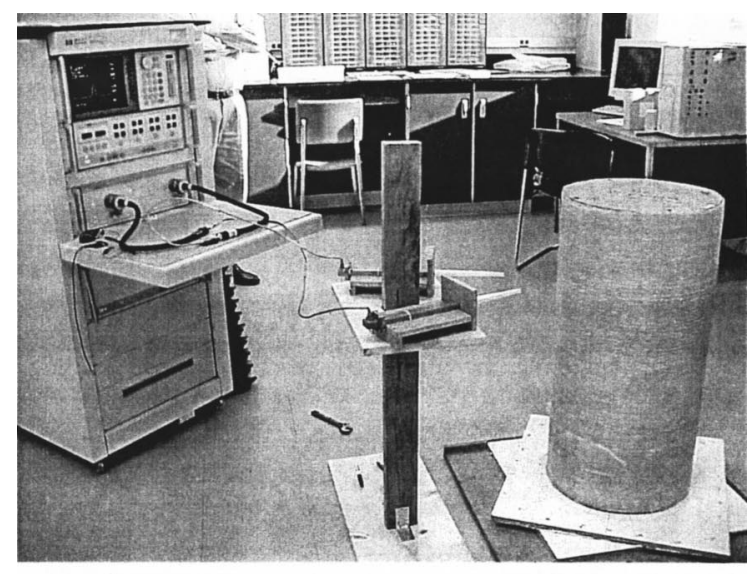

(a) Transmission Measurement $\left(\mathrm{S}_{21}\right)$

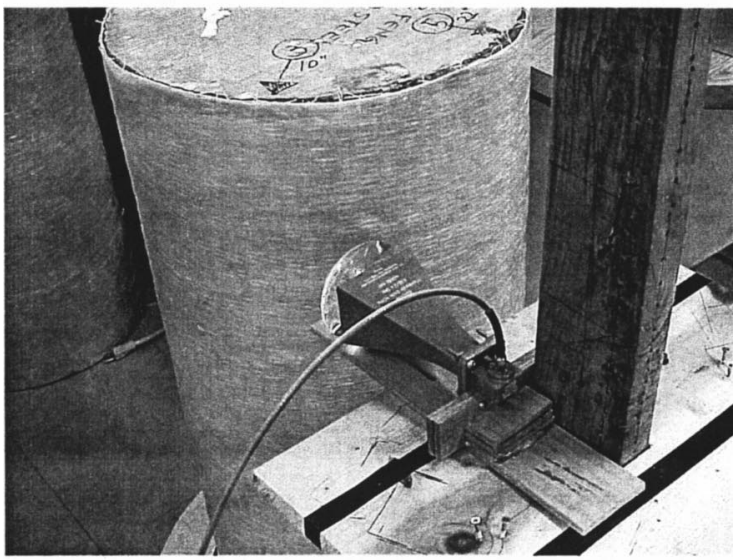

(b) Reflection Measurement $\left(S_{11}\right)$

Fig. 13. Fiber reinforced polymer-jacketed concrete column under testing

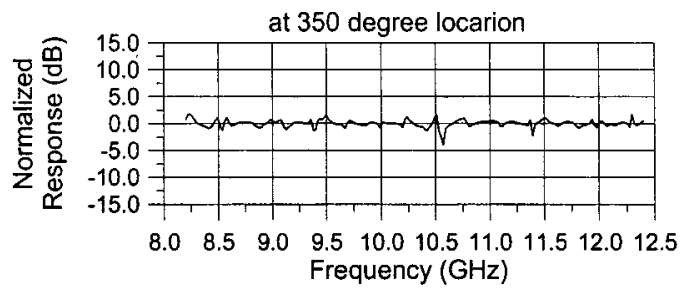

(a) Response from Good Bonding Condition

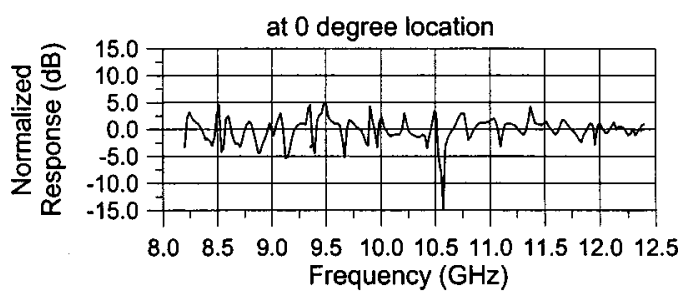

(b) Response from Poor Bonding Condition

Fig. 14. Typical responses using $S_{11}$ measurement

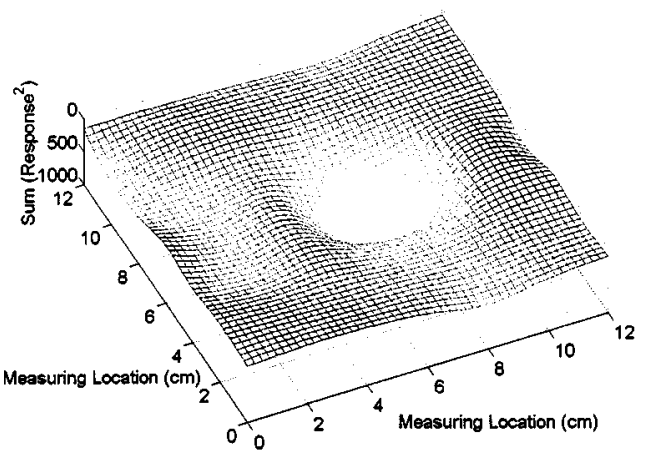

(a) Using Single Circular Lens $\left(S_{11}\right.$ measurement)

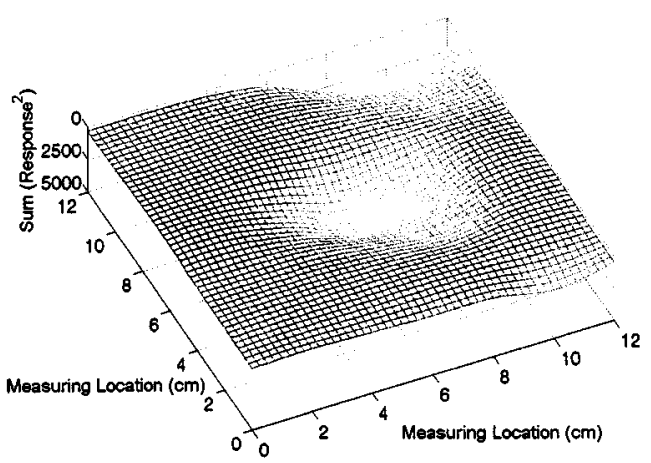

(b) Using Two Triangular Lenses $\left(S_{21}\right.$ measurement)

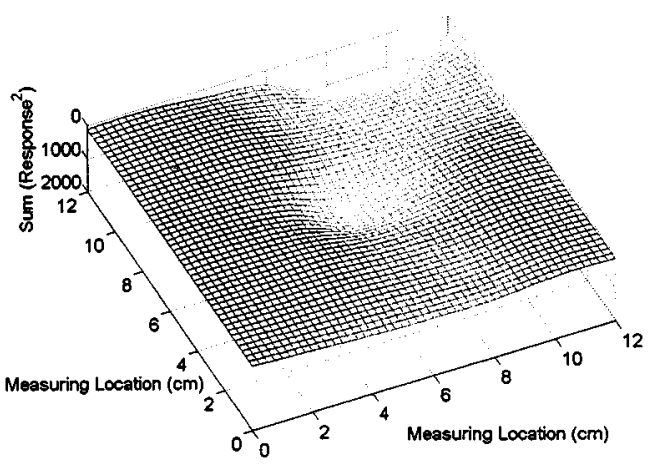

(c) Using Two Circular Lenses $\left(S_{21}\right.$ measurement)

Fig. 15. Scanned images of concrete panel

crete column surface, which was not filled before wrapping the jackets. Others were introduced by inserting a small block or a small strip of Styrofoam in the bonding interface between the jacket and the column or between the two adjacent layers of a jacket. Styrofoam has the same dielectric properties as that of the air. Some of the damage (void/debonding) cases studied in the experiments are listed in Table 2.

\section{Experimental Setup}

Three types of measurement setup were tested; reflection measurement $\left(S_{11}\right)$ using one circular lens, transmission measurement $\left(S_{21}\right)$ using two triangular lenses, and transmission measurement $\left(S_{21}\right)$ using two circular lenses. Fig. 13 (a and b) are two photographs showing one of the columns under testing, respectively, using two triangular lenses for $S_{21}$ measurement and using one circular lens for $S_{11}$ measurement. In the setup shown in Fig. 13(a), two triangular lenses are placed in $40^{\circ}$ with each other on a 


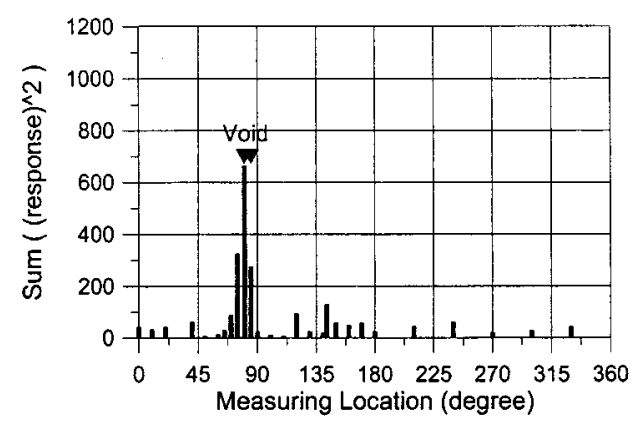

(a) Case 1 Damage

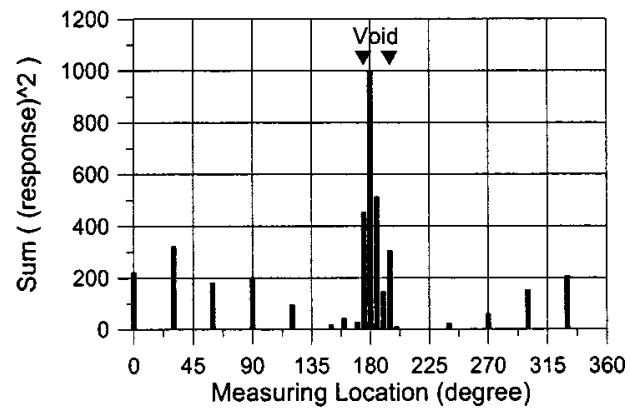

(c) Case 3 Damage

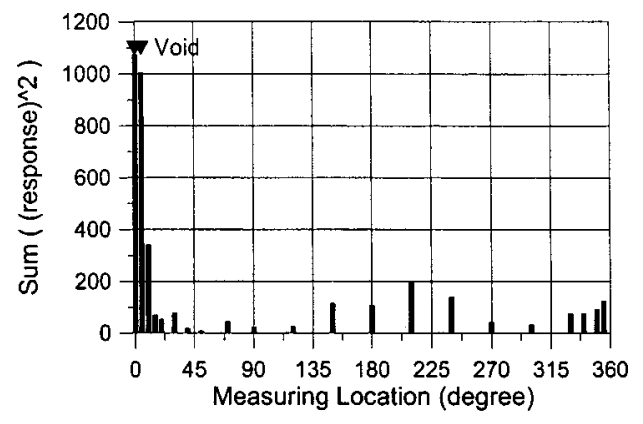

(b) Case 2 Damage

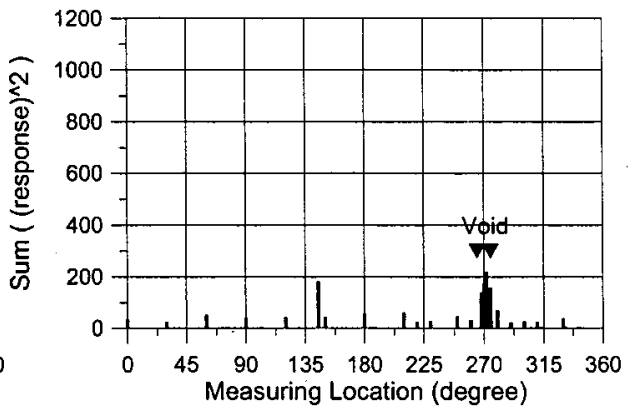

(d) Case 4 Damage

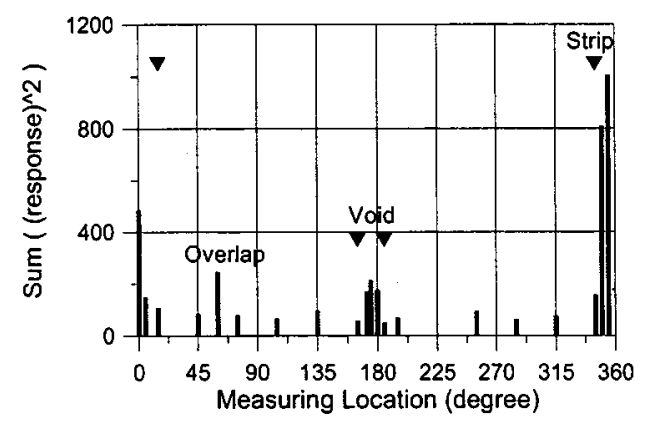

(e) Case 5 and Case 6 Damage

Fig. 16. Results using one circular lens $\left(S_{11}\right.$ measurement $)$

support that can slide up and down. One of the lenses focuses the EM waves originated from the automatic network analyzer on the FRP-jacketed concrete column, while the other lens receives the waves reflected from the column. A turntable is installed on the bottom of each column, making it much easier to rotate the heavy column. With the lenses sliding up and down and the column rotating, the entire surface of the jacketed column can be easily scanned. Obviously, a portable device has to be developed for the field application where the device, not the column, will rotate for scanning the column surface.

The analyzer receives the reflected wave signal from the lens and compares it with a reference value representing a perfect bonding condition through analysis in both time and frequency domains. A computer program was developed in this study for a PC to control the operation of the EM image scan.

\section{Experimental Results}

Continuous sinusoidal EM waves with its frequency sweeping from 8.2 to $12.4 \mathrm{GHz}$ were generated from the signal analyzer and sent to the test specimen. An air gap of as small as $1.051 \mathrm{~mm}$ in concrete can be detected using $12.4 \mathrm{GHz}$ EM waves. Typical frequency-domain responses by an $S_{11}$ measurement using one circular lens are plotted in Fig. 14. The response has been normalized by the reference value representing a perfect bonding condition. It is shown that the response from the poor bonding condition (damage case 2) in Fig. 14(b) has a large variance while the one from the good bonding condition in Fig. 14(a) is almost zero.

The optimal angle between the two lenses for the transmission measurement $\left(S_{21}\right)$ for the best signal receiving quality was investigated through experiments. It was found that the optimal angle was $40^{\circ}$ (i.e., $\theta=20^{\circ}$ ) for the triangular lenses and $90^{\circ}$ (i.e., $\theta=45^{\circ}$ ) for the circular ones. It was also confirmed that the $45^{\circ}$ setup was the best for the reflection measurement $\left(S_{11}\right)$ using one circular lens, as suggested by the simulation analysis presented earlier.

Fig. 15 shows the scanned images of the concrete panel clamped with the FRP sheet, respectively, under the three types of measurement setup with the optimal lens angles. The plotted 


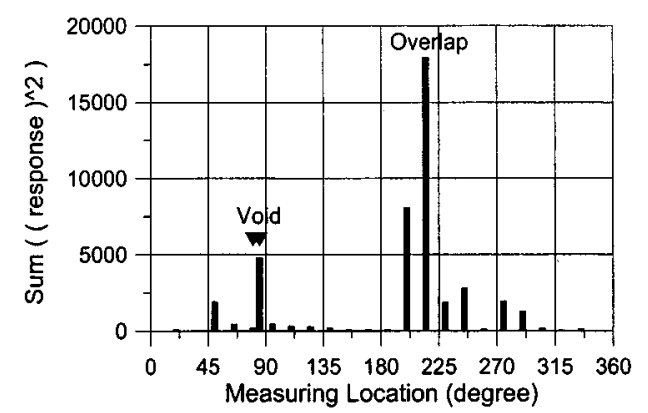

(a) Case 1 Damage

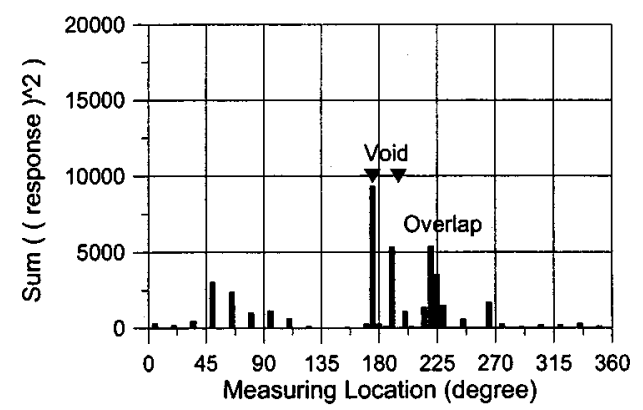

(c) Case 3 Damage

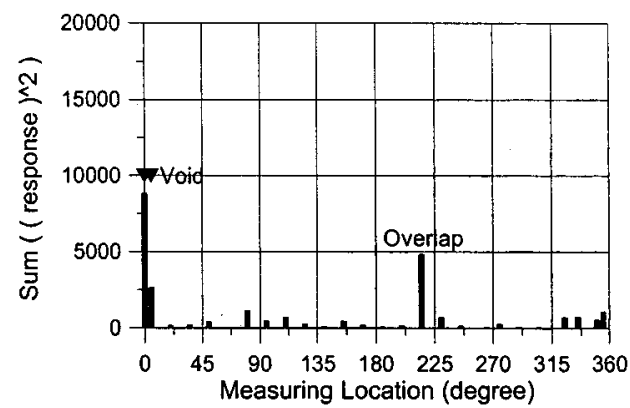

(b) Case 2 Damage

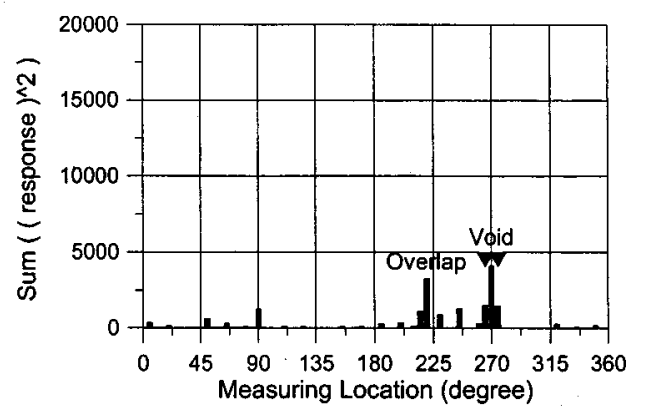

(d) Case 4 Damage

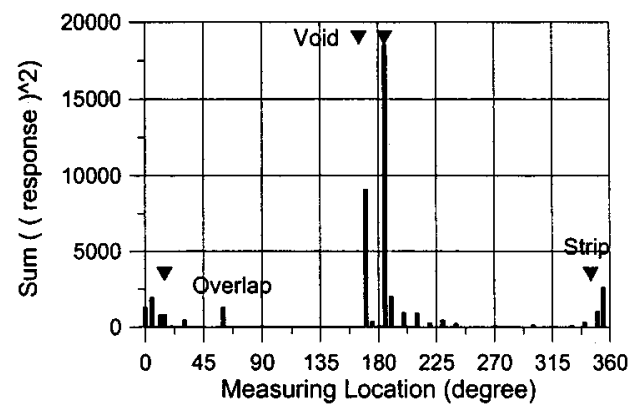

(e) Case 5 and Case 6 Damage

Fig. 17. Results using two triangular lenses ( $S_{21}$ measurement)

value is the sum of the square of the normalized response measured at each measuring point. The scanned image from the $S_{21}$ measurement using two lenses, either circular or triangular, clearly shows the air void resulting from the hole in the concrete surface and the air gap in the edge. On the other hand, the $S_{11}$ measurement using one circular lens successfully detected the hole, but not the air gap in the edge. The $S_{21}$ measurement appeared to be more sensitive than the $S_{11}$ measurement.

Experiments on the FRP-jacketed columns showed that the location and size of the voids on the circular column could also be clearly detected by the focused EM waves. Figs. 16-18 plot the sum of the square of the normalized responses measured at different locations of the column surface, respectively, by the three types of lens setup: $S_{11}$ measurement using one circular lens, $S_{21}$ measurement using two triangular lenses, and $S_{21}$ measurement using two circular lenses, all with the optimal lens angles. The measurement location was defined by the angle of the column rotated about its central axis, and the response was measured at every $5^{\circ}$ with the height of the lens fixed. It is shown that a much larger signal was detected at a damage (void/debonding) location, which is marked with two triangles in Figs. 16-18. It is also noted that the overlap of the FRP sheet at the jacket connection could also result in a large signal. However, by scanning the entire column surface, this type of false reading can be removed because the overlapped portion will appear as a strip from the top to the bottom of the column.

Scanned images using $S_{11}$ and $S_{21}$ measurement are, respectively, shown in Figs. 19(a and b) for a column surface area. The plotted value is the sum of the square of the normalized response measured at each measuring point. This scanned area contains a void between the jacket and the column caused by a hole with a diameter of approximately $2 \mathrm{~cm}$ in the concrete column surface. Although the air void cannot be seen from the outside of the jacket, the scanned EM images clearly identify the location and size of the void. The image produced by the $S_{11}$ measurement is slightly better than that by the $S_{21}$ measurement in the sense that the size and the shape of the void agree better with the reality. The voids and debonding areas at other locations were also successfully detected through scanning the column surface using the developed lenses.

\section{Conclusions}

An EM imaging technology has been developed in this study for detecting such damage as voids and debonding in RC columns 


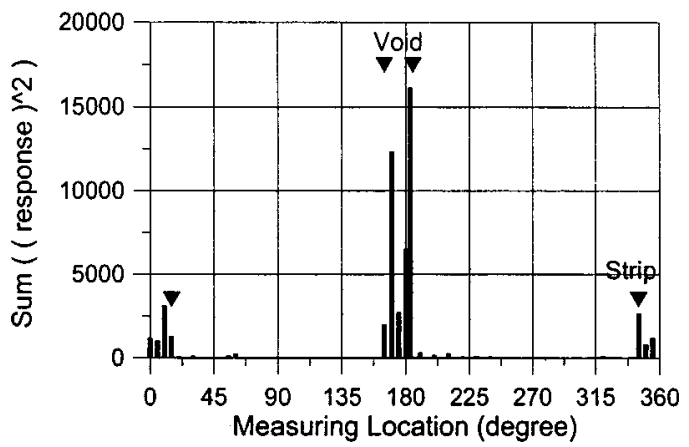

(a) Case 5 and Case 6 Damage

Fig. 18. Results using two circular lenses $\left(S_{21}\right.$ measurement)

retrofitted with FRP jackets. The following conclusions can be drawn from simulation analysis and experiments:

1. The plane EM wave is not capable of detecting the damage.

2. The two types of dielectric lenses developed in this study successfully detected the location and extent of the damage in the bonding interface between the RC column and the FRP jacket, by focusing the EM waves on the interface.

3. Both the reflection $\left(S_{11}\right)$ measurement using a single lens and the transmission $\left(S_{21}\right)$ measurement using two lenses are effective in assessing the bonding condition in the interface between the column and the jacket.

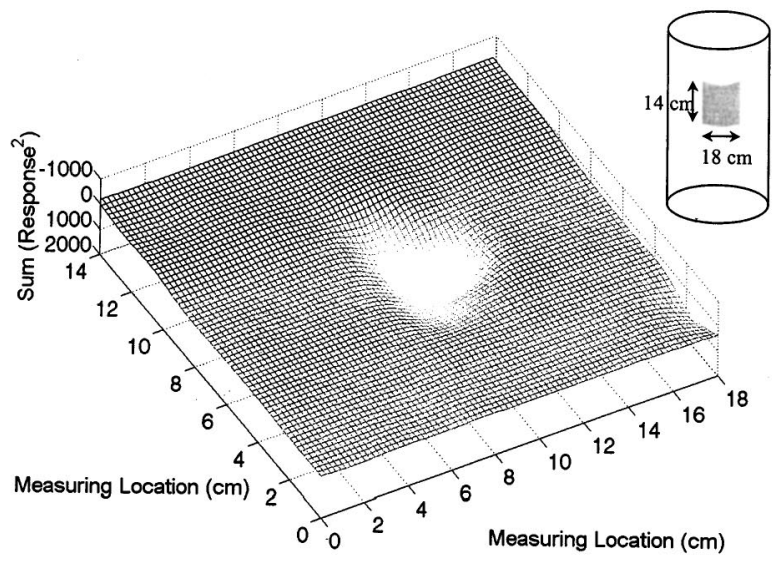

(a) Using Circular Lens $\left(\mathrm{S}_{11}\right)$

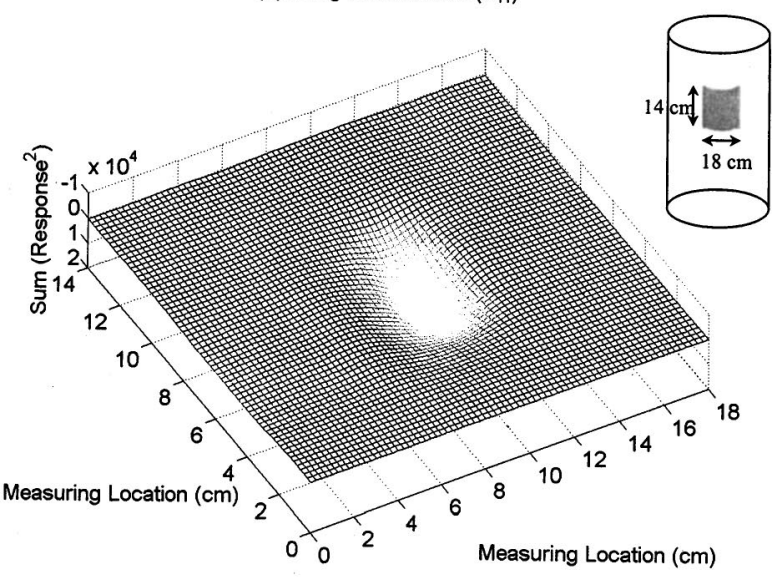

(b) Using Two Triangular Lenses $\left(S_{21}\right)$

Fig. 19. Scanned images of case 2
4. For the $S_{11}$ measurement using a single lens, it is much more effective to place the lens in such a way that the EM wave is sent toward the surface in $45^{\circ}$, rather than in $90^{\circ}$.

5. The special HMDW reflectometer used for measuring dielectric properties of the materials involved in a FRP-jacketed concrete column produced sufficiently accurate results.

The EM imaging technology developed in this study is effective is detecting voids and debonding between a RC column and its FRP jacket. It can be used to assess the jacket bonding quality during the initial jacket installation stage and to detect debonding between the column and the jacket caused by an earthquake and other destructive loads. Extension of the EM imaging technology for detecting internal seismic damage of RC columns covered by FRP jackets will be pursued in the immediate future, in which the interference by the steel reinforcement will be investigated.

\section{Acknowledgments}

This work was supported by the National Science Foundation under Grant Nos. CMS-9812585 and CMS-9812856. The writers would like to thank Professor Rudy Diaz of Arizona State University for his advice about lens design and experimental setup. The writers are also grateful to Professor Ayman Musallam of California State University, Fullerton, for his generous assistance in preparing the test specimen. The writers wish to thank Phraxos R\&D Inc. for making possible the use of the reflectometer. Edge Composites provided the FRP sheets/jackets and Mr. M. Yussef built the concrete columns for the experimental study.

\section{References}

Buyukozturk, O. (1998). "Imaging of concrete structures." NDT \& E Int., 31(4), 233-243.

Chase, S. B., and Washer, G. A. (1997). "Nondestructive evaluation for bridge management in the next century." Public Roads, 60 (July/ August) 16-25.

Feng, M. Q., Liu, C., He, X., and Shinozuka, M. (2000a). "Electromagnetic image reconstruction for damage detection." J. Eng. Mech., 126(7), 725-729.

Feng, M. Q., Flaviis, F. D., Kim, Y. J., and Diaz, R. (2000b). “Application of electromagnetic waves in damage detection of concrete structures." Proc., Int. Symposium on Smart Structures and Materials, SPIE, Newport Beach, Calif., March, 118-126.

Feng, M. Q., and Flaviis, F. D. (2000c). "Advanced Sensors for Condition Monitoring and Damage Assessment for Civil Structures," Proc., Workshop on Mitigation of Earthquake Disaster by Advanced Technologies, Los Angeles, March.

Flaviis, F. D., Noro, M., Diaz, R. E., and Alexopoulos, N. G. (1996). "Diaz-Fitzgerald time domain (D-FTD) technique applied to electromagnetic problem." Proc., IEEE MTT-S Int. Microwave Symposium, San Francisco, June, 1047-1050.

Flaviis, F. D., Noro, M., Diaz, R. E., and Alexopoulos, N. G. (1997). "Diaz-Fitzgerald time domain method applied to electric and magnetic Debye materials." Proc., Applied Computational Electromagnetics, ACES Symposium, Monterey, Calif., March, 17-21.

Flaviis, F. D., Noro, M., Alexopoulos, N. G., Diaz, R. E., and Franceschetti, G. (1998). "Extensions to complex materials of the DiazFitzgerald model for the solution of electromagnetic problems." Electromagnetics, 18, 35-65.

Haroun, M. A., and Feng, M. Q. (1997). "Lap splice and shear enhancements in composite-jacketed bridge columns." Proc., 3rd U.S.-Japan Bridge Workshop, Tsububa, Japan.

Huston, D., Hu, J. Q., Maser, K., Weedon, W., and Adam, C. (2000). "GIMA ground penetrating radar system for monitoring concrete 
bridge decks." J. Appl. Geophys., 43, 139-146.

Johnson, E. C., Nokes, J. P., and Hawkins, G. F. (1999). "NDE of composite seismic retrofits to bridges." Proc., 9th Int. Symposium on Nondestructive Characterization of Materials, Sydney, Australia, 28 June-2 July.

Kundu, T., Ehsani, M., Maslov, K. I., and Guo, D. (1999). "C-scan and L-scan generated images of the concrete/GFRP composite interface." NDT \& E Int., 32(2), 61-69.

Mast, J., Azevedo, S., Hadda, W., Ng, L., and Burnett, G. (1998). "Microwave impulse radar technology and applications." Lawrence Liv- ermore National Laboratory, Rep. No. UCRL-ID-130474.

Olson, L. D., Jalinoos, F., Aouad, M. F., and Balch, A. H. (1993). "Acoustic tomography and reflection imaging for nondestructive evaluation of structural concrete." NSF SBIR Final Report (Award No. 9260840), Washington, DC.

Taflove, A. (1995). Computational Electrodynamics: the FiniteDifference Time-Domain Method, Artech House, Boston.

Yee, K. S. (1966). "Numerical solution of initial boundary value problems involving Maxwell's equations in isotropic media." IEEE Trans. Antennas Propag., 14, 302-307. 